\title{
Abundance of endothelial nitric oxide synthase in newborn intrapulmonary arteries
}

\author{
A A Hislop, D R Springall, L D K Buttery, J S Pollock, S G Haworth
}

\begin{abstract}
A monoclonal antibody to endothelial NOS (eNOS) was used to demonstrate the distribution and density of eNOS in the developing porcine lung. Lung tissue from large white pigs aged from less than 5 minutes to 3 months was immunostained and, using light microscopy, distribution of eNOS was assessed by a semiquantitative scoring system. At all ages eNOS was located on the endothelial cells of pulmonary and bronchial arteries and veins. Immunoreactivity for eNOS was greater in the larger, more proximal pulmonary arteries than at the periphery. In the lung of newborn pigs immunoreactivity for eNOS was present in arteries of all sizes but some showed no positive staining. At 2-3 days of age almost all arteries showed positive immunoreactivity. By 3 months of age the amount of eNOS had decreased and was less than that seen in the newborn. The highest level of eNOS was seen immediately after birth when the pulmonary arteries are dilating. eNOS may therefore play an important part in adaptation to extra-uterine life.

(Arch Dis Child 1995; 73: F17-F21)
\end{abstract}

Keywords: pulmonary circulation, nitric oxide synthase, endothelium.

Persistent pulmonary hypertension of the newborn is associated with the failure of the pulmonary circulation to adapt normally to extra-uterine life. This might be caused by insufficient release of the endothelium derived relaxation factor (EDRF) nitric oxide (NO). ${ }^{1}$ Some babies have been treated successfully using inhaled NO. ${ }^{2}{ }^{3}$ The role of EDRF in the normal process of adaptation is incompletely understood. Acetylcholine stimulation in adult vessels leads, via conversion of $L$-arginine to L-citrulline by nitric oxide synthase (NOS), to the production of $\mathrm{NO}$ and thence to an increase in smooth muscle cell $3^{\prime}-5^{\prime}$-cyclic guanosine monophosphate (cGMP), causing relaxation. ${ }^{4}$ The endothelial dependent relaxant response to acetylcholine is absent at birth in porcine intrapulmonary arteries, ${ }^{5}$ and relatively poor in ovine vessels. ${ }^{6}$ By 3 days of age, in piglets the response to acetylcholine is present and greater than in the adult. ${ }^{5}$ Inhaled NO leads to a drop in pulmonary artery pressure in 1 to 2 day old piglets made hypertensive by hypoxia. ${ }^{7}$ As it is not possible to study human lungs and because previous studies have shown that the structural and functional changes that occur after birth are similar in porcine and human pulmonary arteries, ${ }^{8}$ the present study in pigs was carried out to determine whether changes in the amount and localisation of endothelial NOS (eNOS) in newborn intrapulmonary arteries would help explain the lack of response to acetylcholine.

NOS has several isoforms; the one produced by the endothelial cells is known as type III, and is constitutive, calcium-calmodulin dependent and primarily particulate. ${ }^{9} \mathrm{~A}$ recent study on rat lung membranes has demonstrated an increase in NOS III protein and mRNA during late gestation, with a decrease in the immediate postnatal period. ${ }^{10} \mathrm{We}$ used a monoclonal antibody to constitutive NOS extracted from cultured bovine aortic endothelial cells, known to show immunoreactivity to porcine tissue. ${ }^{11}$ Immunocytochemical studies were carried out on fresh lung tissue obtained from normal piglets at intervals from birth ( $<5$ minutes) to 3 months of age.

\section{Methods}

Lung tissue was obtained from 29 healthy large white pigs aged $<5$ minutes $(n=5), 2$ days $(n=4), 3$ days $(n=5), 5$ days $(n=3), 10$ days $(n=7)$, and 3 months $(n=5)$. For each age group, animals were obtained from different litters. The investigation conforms with the Guide for the care and use of laboratory animals published by the US National Institutes of Health (NIH publication No 85-23; revised 1985). Within five minutes of death slices of tissue from the mid-lung region were immersed in freshly defrosted $1 \%$ paraformaldehyde solution in phosphate buffered saline (PBS: 0.01 M phosphate buffer, $\mathrm{pH} 7 \cdot 4$, with $0.15 \mathrm{M}$ sodium chloride) for four hours and then washed in PBS containing $10 \%$ sucrose for at least 24 hours. After snap freezing, sections $7 \mu \mathrm{m}$ thick were cut at $21^{\circ} \mathrm{C}$ in a cryostat. Sections were immersed in $0.03 \%$ hydrogen peroxide in methanol for 30 minutes to block endogenous peroxidase, followed by three 10 minute washes in PBS. Non-specific binding was blocked by incubation in 3\% normal horse serum for 20 minutes. Sections were then blotted to remove excess serum and incubated overnight with a mouse monoclonal antibody to purified bovine aortic endothelial cell NOS diluted 1 in 10000 in PBS containing $0.05 \%$ bovine serum albumin (BSA) and $0.1 \%$ sodium azide. After washing in PBS, sections were successively incubated with biotinylated horse antiserum to mouse IgG (Vector Laboratories, Burlingame, CA, USA) diluted 1 in 100 in PBS with BSA and freshly prepared avidin-biotinylated-peroxidase complex (Vector Laboratories) for 30 and 60 minutes, 


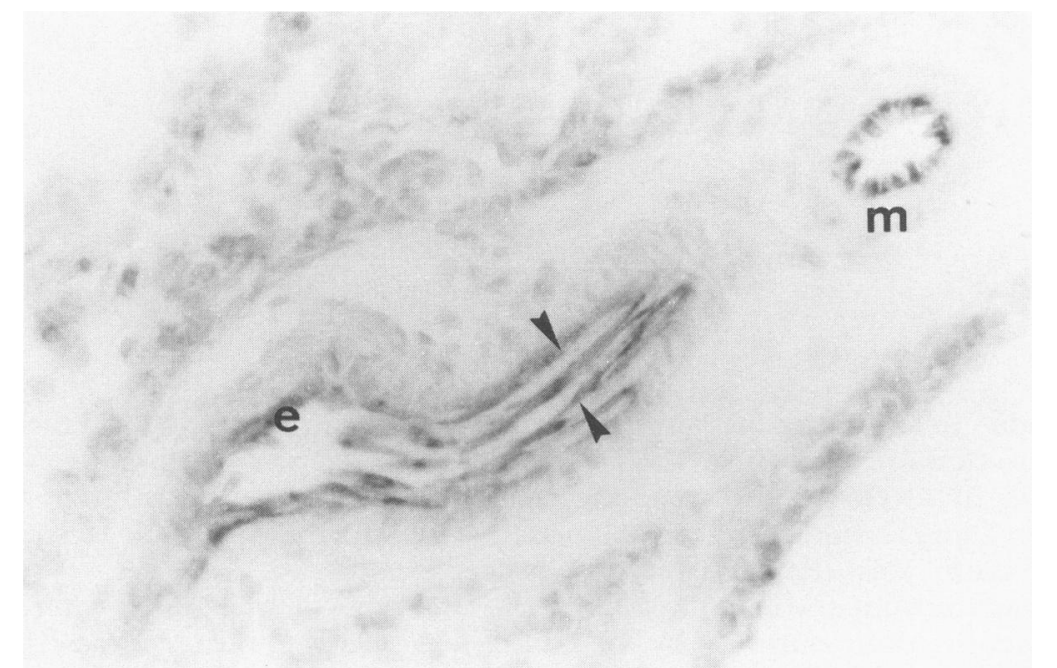

Figure 1 Photomicrograph of a small pulmonary artery from a newborn piglet. Positive eNOS reactivity is seen in the endothelial cells. The density of staining is particularly strong around the periphery of the cells when they are seen en face at arrows. $e=e n d o t h e l i u m$, $m=$ media.
$51-100 \%$ of their endothelial cells containing NOS the score would be 100 . A mean score for each type of artery in each age group was calculated. Because this was a derived figure no statistical methods were used.

\section{Results}

NOS was located on the endothelial cells of the pulmonary arteries and veins and the systemic bronchial arteries and veins. The eNOS immunoreactivity was more dense around the edges of the cells particularly when the cells were viewed en face (fig 1 ). In the pulmonary arteries the number of cells stained and the density of staining varied with respect to the position of the artery in the branching pathway and with age. By contrast, in pulmonary veins and in the bronchial arteries and veins most endothelial cells contained eNOS at all ages. In the newborn lungs most of the pulmonary arteries accompanying peripheral airways showed some positive immunoreactivity for eNOS, while in the alveolar region only a small number of arteries did so (fig 2). The arteries of the 2 and 3 day old animals showed a stronger immunoreactivity in all vessels than was present at birth, including most of the arteries in the alveolar region (fig 3). By 5 and 10 days of age the amount of staining was similar to that seen at birth. By 3 months of age, when the pulmonary blood vessels have an adult wall structure, ${ }^{13}$ there was little staining in the endothelial cells of the arteries in the alveolar region (fig 3), although the larger arteries and all the veins still showed positive immunoreactivity. of artery were identified: (1) arteries accompanying bronchioli; (2) arteries accompanying terminal bronchioli; (3) arteries accompanying respiratory bronchioli; (4) arteries accompanying alveolar ducts; and (5) arteries accompanying alveoli. For each artery the amount of NOS was assessed as: (i) none; (ii) up to $50 \%$ of the endothelial cells containing eNOS; or (iii) $51-100 \%$ of the endothelial cells containing eNOS. For each of the five types of artery, the percentage falling into the three groups was determined. At least 20 arteries of each type were assessed in each animal and in the alveolar duct and alveolar region, at least 50. This assessment was made without the examiner knowing the age of the piglet tissue being examined, and confirmed independently by a co-author.

For each age group and each type of artery, the mean value of each of the three percentage groups was determined and the results compared using ANOVA, and, where appropriate, Student's $t$ test with Bonferroni's correction for multiple comparisons. A $P$ value of $<0.05$ was regarded as having a significant difference.

From these data an average score for the amount of eNOS in the lung tissue was derived in order to help understanding. By multiplying the percentage of vessels with no eNOS by 0 , vessels with $1-50 \%$ by 0.5 , and vessels with $51-100 \%$ by 1 , and adding them together, a score out of 100 was produced for each type of artery. Thus if all arteries studied had

\section{SEMIQUANTITATIVE ASSESSMENT (table)}

The amount of eNOS immunoreactivity was greater in larger and more proximal arteries at all ages, with respect to the percentage of arteries which contained eNOS and to the number of endothelial cells in each vessel showing eNOS immunoreactivity. At the level of the bronchioli, at all ages, most arteries had $51-100 \%$ of the endothelial cells staining positively for eNOS and only very few showed no eNOS reactivity (0-7\% for the six age groups). At terminal bronchiolar level there were more arteries with no eNOS reactivity and this number was further increased at respiratory bronchiolar level (1-14\%, for the age groups). For arteries at bronchiolar and respiratory bronchiolar level, the percentage of arteries containing $51-100 \%$ of cells with eNOS was significantly higher at 2 days of age than at 3 months $(p<0.05)$.

At alveolar duct level $77 \%$ of arteries showed some eNOS reactivity at birth. By 3 days of age all arteries contained eNOS in their endothelium. However, by 3 months of age fewer arteries than at birth had any eNOS present. In the arteries lying within the alveolar walls a third of arteries had no eNOS reactivity at birth. By 3 days only $1 \cdot 7 \%$ had none. Conversely, arteries with $51-100 \%$ of their endothelial cells containing NOS increased in number from birth and at 2 and 3 days there 


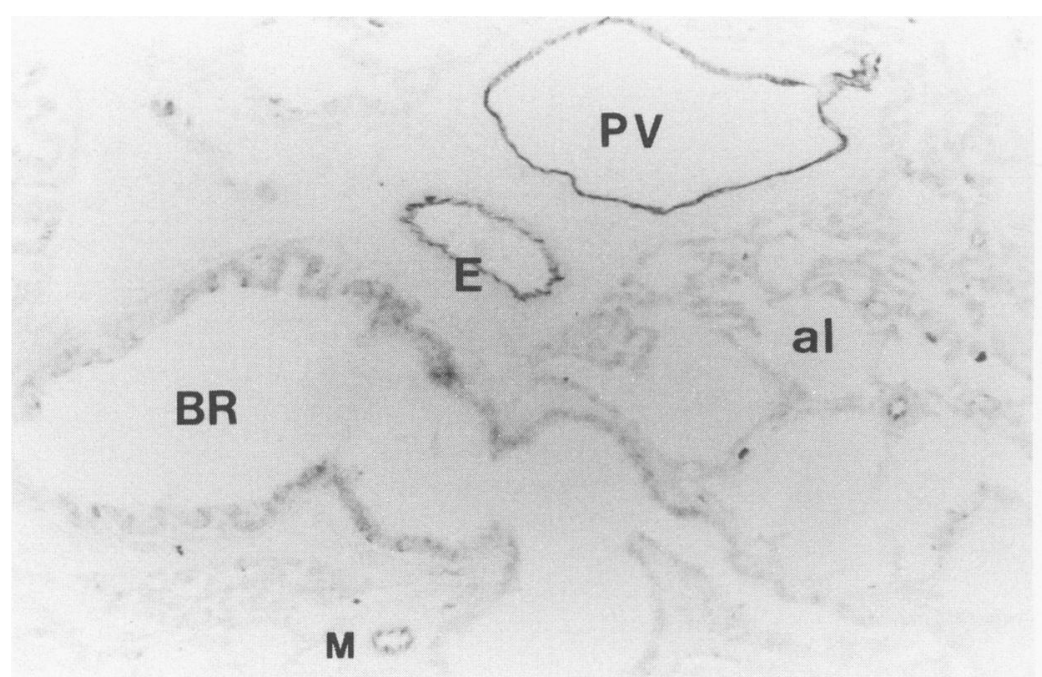

Fig $2 A$

Figure 2 Photomicrographs of newborn piglet lung. (A) Low magnification: an airway $(B R)$ is accompanied by an elasic walled artery (E) with endothelium positive for eNOS. A small muscular artery (M) has fewer cells positive for eNOS. The pulmonary vein (PV) has an endothelium that is totally positive. Within the alveolar region (al) are small arteries with some positive immunoreactivity. (B) Elastic pulmonary artery wall; all endothelial cells show presence of eNOS. (C) Pulmonary vein of similar size to the elastic artery in (B); all endothelial cells show presence of eNOS.

were significantly more than at 3 months of age $(\mathrm{P}<0 \cdot 05,2$ and 3 days $v 3$ months).

The derived mean score for the amount of eNOS at each level related to age is shown in fig 4 . The score was generally greater in more proximal arteries at all ages. In all types of intrapulmonary artery the score increased between birth and 2 to 3 days of age, and then decreased. The greatest changes were seen in the alveolar wall arteries where the score increased from 56 in the newborn to 98 at 3 days, and then decreased to 29 at 3 months of age.

Thus the overall amount of eNOS in the pulmonary arterial endothelial cells increases between birth and 2 to 3 days, followed by a gradual decrease to the lower level found in the mature lung.

\section{Discussion}

Using the monoclonal antibody to type III endothelial NOS, we have demonstrated the presence of eNOS in the porcine intrapulmonary and bronchial arteries and veins, from birth to 3 months of age when the structure of the pulmonary arteries is mature. ${ }^{13}$ eNOS was located only on the endothelial cells of the vessel wall, as reported in other organs and other species. ${ }^{14}$ The immunostaining for eNOS was pronounced at cell margins but was present throughout the cytoplasm. A previous electron microscopic study showed that NOS was localised to the plasma membranes of human umbilical vein endothelial cells. ${ }^{14}$

The presence of abundant eNOS at birth (greater than in the 3 month old piglet) suggests that porcine pulmonary arteries and veins have the ability to produce NO from the moment of birth. We know that there is a high basal level of cGMP at birth. ${ }^{15}$ Perreault and de Marte demonstrated the presence of a basal level of NO in the pulmonary circulation of

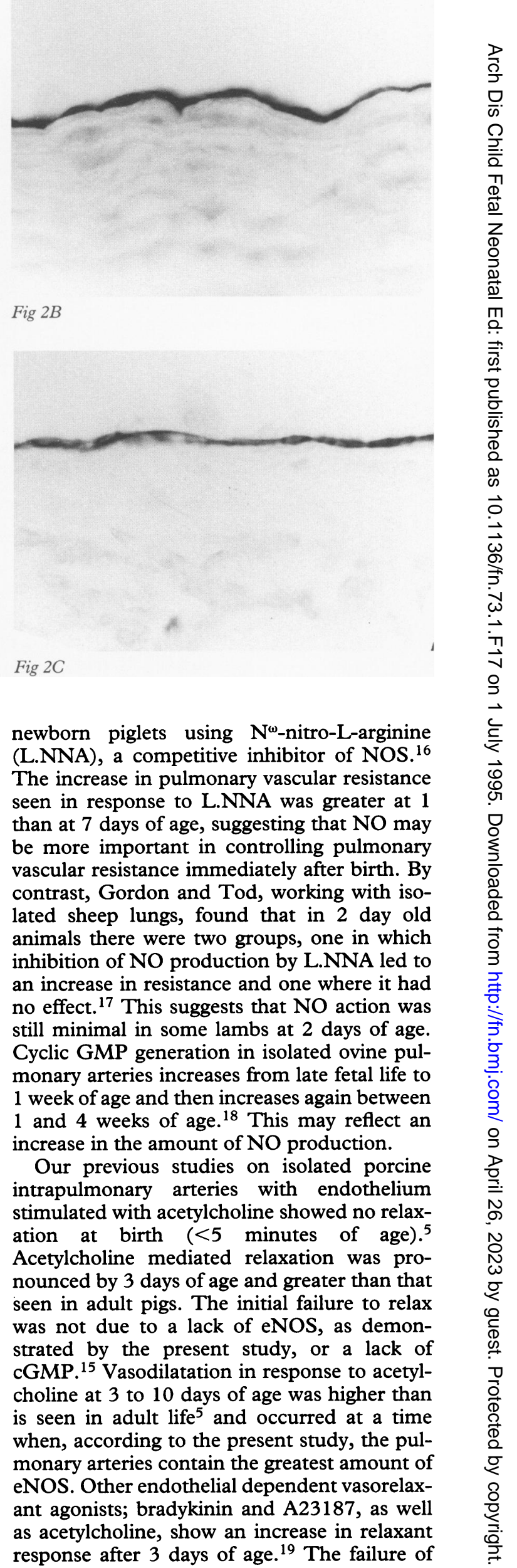
acetylcholine to effect relaxation at birth in 


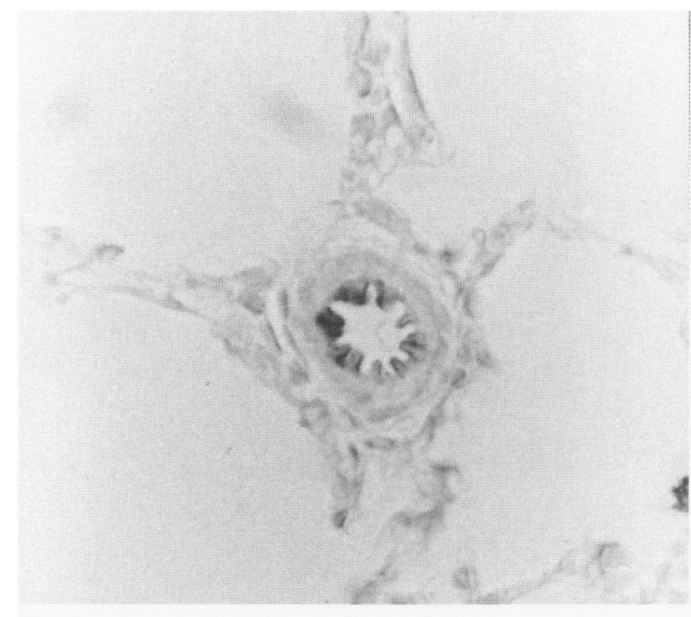

Fig $3 A$

Figure 3 Photomicrographs of alveolar wall arteries $(A)$ at birth, (B) 3 days, and (C) 3 months of age. eNOS immunoreactivity is seen in the endothelial cells. In the newborn the density of staining varies between cells and $50-100 \%$ of the cells show some positive staining. At three days all cells show a dense stain throughout the cytoplasm. At three months, in this artery, only one cell shows positive staining throughout the cytoplasm with less than $50 \%$ of the cells showing any stain.

piglets seems to be due to immaturity of the receptor itself or to a difference in the relaxant signal transduction mechanism in the immature lung, rather than a lack of eNOS or capacity to release NO by the endothelial cells. The failure to respond to acetylcholine is unlikely to be due to an inability of the smooth muscle cells to relax as the arteries from the newborn pig relax in response to sodium nitroprusside. $^{5}$

The present study showed regional as well as age related differences in the amount of eNOS. Such regional differences may have functional implications. Abman ${ }^{6}$ and Steinhorn ${ }^{20}$ demonstrated minimal relaxation to acetylcholine in isolated conduit arteries in fetal and newborn sheep, while they have shown a good response in the intact fetus and newborn, ${ }^{21}$ suggesting greater release of NO from peripheral vessels involved in the whole lung preparation. Similarly, isolated rings of porcine intrapulmonary arteries showed no response at birth to acetylcholine, ${ }^{5}$ but relaxation was present by 3

Distribution of eNOS staining: percentage of arteries (standard deviation) containing different amounts of eNOS within the endothelial cells

\begin{tabular}{|c|c|c|c|c|c|c|}
\hline $\begin{array}{l}\text { Artery } \\
\text { level (\%) }\end{array}$ & Newborn & 2 Days & 3 Days & 5 Days & 10 Days & 3 Months \\
\hline \multicolumn{7}{|c|}{ Bronchiolus: } \\
\hline 0 & $0.8(1.6)$ & & & $6 \cdot 7(9 \cdot 4)$ & $1.85(3.2)$ & $3(2 \cdot 5)$ \\
\hline $1-50$ & $23 \cdot 2(8 \cdot 7)$ & $9 \cdot 25(4 \cdot 96)$ & $24 \cdot 2(12)$ & $36 \cdot 7(6.9)$ & $40 \cdot 1(6 \cdot 7)$ & $33.9(7 \cdot 7)$ \\
\hline $51-100$ & $76(9 \cdot 4)$ & $90.75(4.96)$ & $75 \cdot 8(12)$ & $56.7(14.9)$ & $58(6 \cdot 3)$ & $63 \cdot 1(8 \cdot 7)$ \\
\hline \multicolumn{7}{|c|}{ Terminal bronchiolus: } \\
\hline 0 & $8 \cdot 4(16 \cdot 8)$ & $2(3 \cdot 5)$ & 0 & $6(4 \cdot 3)$ & $1 \cdot 6(3 \cdot 8)$ & $6(4 \cdot 9)$ \\
\hline $1-50$ & $36 \cdot 7(7 \cdot 1)$ & $10 \cdot 25(9 \cdot 1)$ & $35(30)$ & $40(8 \cdot 2)$ & $50 \cdot 6(16 \cdot 7)$ & $29 \cdot 1(15 \cdot 7)$ \\
\hline $51-100$ & $54.9(16.4)$ & $87.75(9.3)$ & $65(30)$ & $54(7 \cdot 4)$ & $47 \cdot 7(16 \cdot 6)$ & $64.9(19.3)$ \\
\hline \multicolumn{7}{|c|}{ Respiratory bronchiolus: } \\
\hline 0 & $12 \cdot 6(14 \cdot 6)$ & $1 \cdot 25(2 \cdot 2)$ & $1 \cdot 6(3 \cdot 2)$ & $4 \cdot 7(6 \cdot 6)$ & $4 \cdot 6(8 \cdot 9)$ & $14(5 \cdot 1)$ \\
\hline $1-50$ & $41.6(13.4)$ & $15 \cdot 25(10 \cdot 3)$ & $31 \cdot 2(25)$ & $45 \cdot 3(6 \cdot 6)$ & $64 \cdot 6(19 \cdot 2)$ & $54 \cdot 8(8 \cdot 7)$ \\
\hline $51-100$ & $45.8(17.5)$ & $83.5(11.9)$ & $67 \cdot 2(25)$ & 50 & $30.9(18.9)$ & $31 \cdot 2(5 \cdot 5)$ \\
\hline \multicolumn{7}{|c|}{ Alveolar duct: } \\
\hline 0 & $23.4(21 \cdot 1)$ & $1(1 \cdot 6)$ & 0 & $6 \cdot 7(4 \cdot 6)$ & $10 \cdot 7(9 \cdot 8)$ & $28 \cdot 4(4 \cdot 3)$ \\
\hline $1-50$ & $31(4 \cdot 9)$ & $21 \cdot 25(4 \cdot 7)$ & $26(22)$ & $48(2 \cdot 1)$ & $47.6(13.8)$ & $43(10 \cdot 2)$ \\
\hline \multicolumn{7}{|l|}{$\begin{array}{l}51-100 \\
\text { Alveoli: }\end{array}$} \\
\hline & $31(27 \cdot 3)$ & $4(3 \cdot 7)$ & $1.7(3.4)$ & $40(43 \cdot 2)$ & $31.9(26.8)$ & $54(9 \cdot 2)$ \\
\hline $1-50$ & $25 \cdot 2(19 \cdot 8)$ & $18.75(6.6)$ & $16 \cdot 7(18)$ & $17(12 \cdot 8)$ & $37 \cdot 6(10 \cdot 1)$ & $31 \cdot 4(4 \cdot 7)$ \\
\hline $51-100$ & $43.8(22.9)$ & $77 \cdot 25(5 \cdot 3)$ & $81 \cdot 6(18)$ & $43(30 \cdot 3)$ & $30.6(18.7)$ & $13.6(10 \cdot 3)$ \\
\hline
\end{tabular}

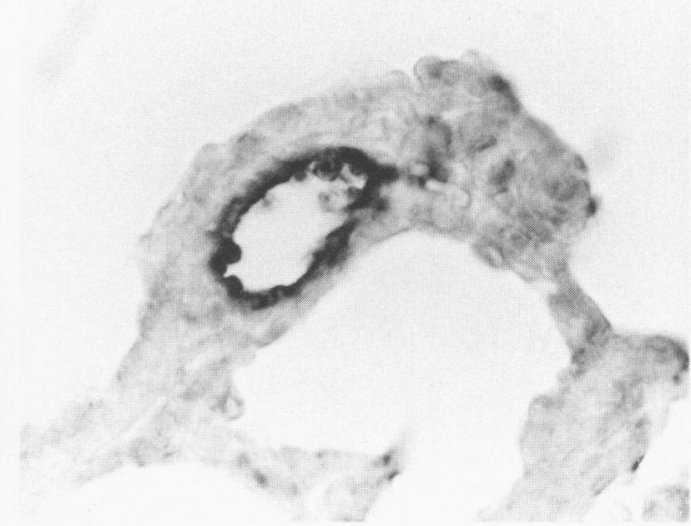

Fig $3 B$

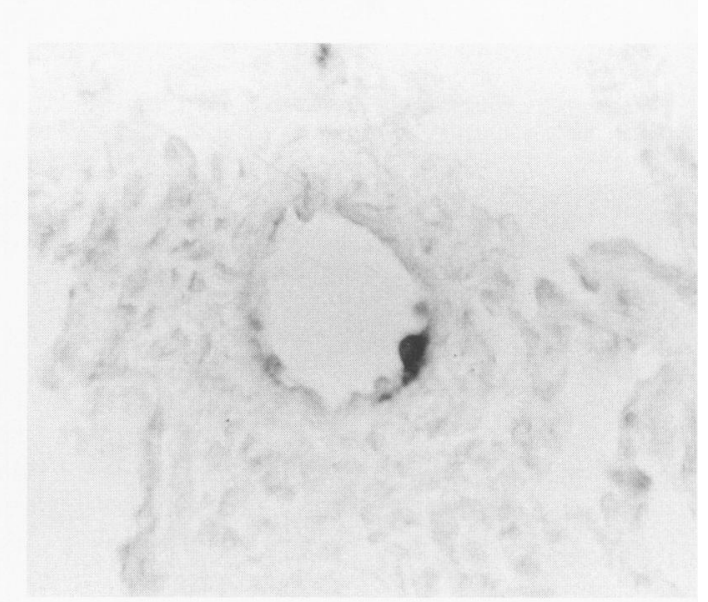

Fig 3C

days of age, ${ }^{519}$ while whole lung preparations showed greater baseline production of NO at 1 than at 7 days of age. ${ }^{16}$ The present study has shown that failure of the large intrapulmonary arteries to dilate is not due to an absence of eNOS. However, the presence of eNOS in the endothelial cells does not mean that it has an active role, and failure of stimulation by receptor mechanisms may prevent the dilatation of these large arteries in vitro.

While the amount of eNOS in arteries varied according to the type of intrapulmonary artery and age, in the pulmonary veins the distribution and amount of eNOS immunoreactivity did not change. These morphological

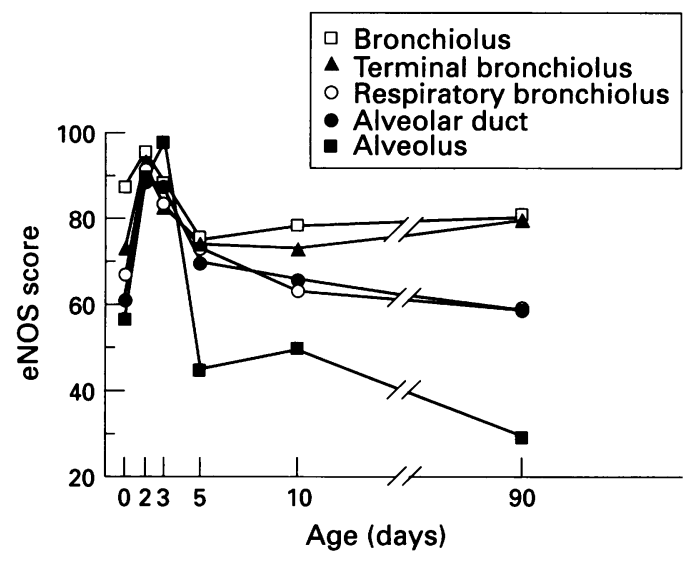

Figure 4 Mean score for NOS related to age for each arterial level. 
findings in the pig agree with pharmacological studies on the ovine lung in which a similar high level of basal NO production is seen in veins from 2 day and 1 month old animals, ${ }^{17}$ suggesting little maturational change. Work on whole lung preparations of lambs has indicated that the contribution of the veins in maintaining a relatively low pulmonary vascular resistance is greater than that of the arteries in the lungs from newborn animals. ${ }^{20}$

In the porcine lung the overall level of eNOS, as shown by the scoring system, is highest two to three days after birth. The greatest immunoreactivity was found at the time when acetylcholine stimulated relaxation via EDRF is maximal. ${ }^{5}$ The high level of eNOS may therefore be important in postnatal adaptation. In humans persistent pulmonary hypertension of the newborn is characterised by the persistence of the thick walled pulmonary arterial wall structure of fetal life. The failure to vasodilate may be due to a lack of eNOS at birth, or failure to increase eNOS production for some reason. The effect of hypoxia on the endothelial NOS of the newborn lung is now being investigated.

We acknowledge the careful technical assistance of Mrs $\mathrm{H}$ Oliveira.

This work was supported by the British Heart Foundation.

1 Furchgott RF, Zawadzki JV. The obligatory role of endothelial cells in the relaxation of arterial smooth muscle by lial cells in the relaxation of arterial smo

2 Roberts JD, Polaner DM, Lang P, Zapol WM. Inhaled nitric oxide in persistent pulmonary hypertension of the nitric oxide in persistent pulmonary

3 Kinsella JP, Neish SR, Shaffer E, Abman SH. Low-dose inhalational nitric oxide in persistent pulmonary hypertension of the newborn. Lancet 1992; 340: 819.

4 Forstermann U, Mulsch A, Bohme E, Busse R. Stimulation of soluble guanylate cyclase by an acetylcholine-induced endothelium derived factor from rabbit and canine arteries. Circ Res 1986; 58: 531-8.

5 Liu SF, Hislop AA, Haworth SG, Barnes PJ. changes in endothelium-dependent 106: $324-30$.
6 Abman SH, Chatfield BA, Rodman DM, Hall SL, McMurtry IV. Maturational changes in endotheliumderived relaxing factor activity of ovine pulm

7 Etches PC, Finer NN, Barrington KR, Graham AJ, Chan WKY. Nitric oxide reverses acute hypoxic pulmonary hypertension in the newborn piglet. Pediatr Res 1994; 35: 15-9.

8 Haworth SG, Hislop AA. Adaptation of the pulmonary circulation to extra-uterine life in the pig and its relevance to the human infant. Cardiovasc Res 1981; 15: 108-19.

9 Forstermann U, Pollock JS, Schmidt HW, Heller M, Murad F. Calmodulin-dependent endothelium-derived relaxing factor/nitric oxide synthase activity is present in the particulate and cytosolic fractions of bovine aortic endothelial cells. Proc Natl Acad Sci USA 1991; 88: 1788-92.

10 North AJ, Star RA, Brannon TS, Ujiie K, Wells LB, Lowenstein CJ, et al. Nitric oxide synthase type I and type III gene expression are developmentally regulated in rat III gene expression are developmentally

11 Pollock JS, Forstermann U, Mitchell JA, Warner TD, Schmidt HHHW, Nakane M, et al. Purification and characterisation of particulate endothelium-derived relaxing factor synthase from cultured and native bovine aortic endothelial cells. Proc Natl Acad Sci USA 1991; 88: 10480-4.

12 Shu S, Ju G, Fan L. The glucose oxidase-DAB-nickel method in peroxidase histochemistry of the nervous system. Neurosci Lett 1988; 85: 169-71.

13 Hall SM, Haworth SG. Normal adaptation of pulmonary arterial intima to extrauterine life in the pig: ultrastructural studies. $\mathcal{P}$ Pathol 1986; 149: 55-66.

14 Pollock JS, Masaki N, Buttery LDK, Martinez A, Springall D, Polak JM, et al. Characterization and localization of endothelial nitric oxide synthase using specific ization of endothelial nitric oxide synthase using specific
monoclonal antibodies. $A m$ f Physiol 1993; 265: monoclonal

15 Tulloh RMR, Boels PJ, Hodgson PE, Haworth SG. Chronic Hypoxia alters contractile and relaxant responses in isolated intrapulmonary arteries of the newborn pig. Am $\mathcal{F}$ Respir Crit Care Med 1994; 149: A26.

16 Perreault T, De Marte J. Maturational changes in endothelium-derived relaxations in newborn piglet pulmonary circulation. Am ₹ Physiol 1993; 264: H302-9.

17 Gordon JB, Tod ML. Effects of N-nitro-L-arginine on total and segmental vascular resistances in developing lamb lungs. $\mathcal{F} A$ ppl Physiol 1993; 75: 76-85.

18 Shaul PW, Farrar MA, Magness RR. Pulmonary endothelial nitric oxide production is developmentally regulated in the fetus and newborn. Am $\mathcal{F}$ Physiol 1993; 265: the fetus

19 Zellers TM, Vanhoutte PM. Endothelium-dependent relaxations of piglet pulmonary arteries augment with maturation. Pediatr Res 1991; 30: 176-80.

20 Steinhorn RH, Morin III FC, Gugino SF, Giese EC, Russell JA. Developmental differences in endotheliumdependent responses in isolated ovine pulmonary arteries and veins. Am $\mathcal{F}$ Physiol 1993; 264: H2162-7.

21 Abman SH, Chatfield BA, Hall SL, McMurtry IF. Role of endothelium-derived relaxing factor during transition of pulmonary circulation at birth. F Physiol 1990; 259: H1921-7. 